\title{
Galanthus ikariae Baker Bitkisinin Toprak Üstü Kısımlarının Uçucu Yağının Kimyasal Bileşimi ve Biyolojik Aktiviteleri
}

\author{
Chemical Constituents and Biological Activities of Essential Oil from Aerial Parts of \\ Galanthus ikariae Baker
}

\author{
Osman ÜÇÜNCÜ̈ ${ }^{* 1, a}$, Cemalettin BALTACI ${ }^{1, \mathrm{~b}}$, Şeyda Merve KARATAŞ ${ }^{1, \mathrm{c}}$, Ayşe MUSLU ${ }^{1, \mathrm{~d}}$, Demet \\ BÜYÜKÇEKİÇ ${ }^{1, \mathrm{e}}$, Hasan EJDERHA ${ }^{1, f}$, Elif Ezgi ÖZDEMİR ${ }^{1, \mathrm{~g}}$ \\ ${ }^{1}$ Gümüşhane Üniversitesi, Mühendislik ve Doğa Bilimleri Fakültesi, Glda Mühendisliği Bölümü, 29100, Gümüşhane
}

• Geliş tarihi / Received: 12.02.2019 • Düzeltilerek geliş tarihi / Received in revised form: 13.06.2019 • Kabul tarihi / Accepted: 21.06 .2019

$\ddot{O} z$

Bu çalışmada Galanthus ikariae Baker bitkisinin toprak üstü kısımlarının uçucu yağının kimyasal içeriği, antioksidan ve antimikrobiyal özellikleri araştırılmıştır. Bitkinin uçucu yağı Clevenger tipi hidrodistilasyon ile alınmış ve GCMS/FID ile analiz edilmiştir. Uçucu yağdaki 41 bileşiğin yapısı literatür bilgileri ile karşılaştırılarak aydınlatılmıştır. Hegzadekanoik asit, linoleik asit, 2-tridekanon ve linoleik asit metil ester bileşiklerinin sırasıyla \%19.05; \%14.6; \%11.49 ve \%6.97 oranlarında ana bileşenler oldukları tespit edilmiştir. Uçucu yağın toplam fenolik miktarı ve radikal süpürücü aktivitesi (DPPH) sırasıyla $342.22 \mathrm{mg} / \mathrm{mL}$ GAE ve $\% 55.92$ bulunmuştur. Uçucu yağın antimikrobiyal aktivitesi agar kuyucuk metodu ile 12 adet bakteri ve 5 adet maya-küfe karşı araştırılmıştır ve özellikle Listeria monocytogenes bakterisi ve Saccharomyces cerevisiae mayasına karşı etkili olduğu görülmüştür.

Anahtar kelimeler: Antimikrobiyal, Antioksidan, Galanthus ikariae, GS-MS/FID, Uçucu Yağ

\begin{abstract}
In this study, the chemical composition, antioxidant and antimicrobial properties of the volatile oil of aerial parts Galanthus ikariae Baker plant were investigated. The essential oil was obtained by Clevenger type hydrodistillation and analysed by GC-MS/FID. The structures of 41 compounds in essential oil were compared with the literature information. Hexadecanoic acid, linoleic acid, 2-tridecanone and linoleic acid methyl ester compounds were the main components and found as $19.05 \% ; 14.67 \% ; 11.49 \%$ and $6.97 \%$, respectively. The amount of total phenolic and, $\%$ DPPH' scavenging activity were found as $342.22 \mathrm{mg} / \mathrm{mL} \mathrm{GAE}$ and $\% 55.92$, respectively. The antimicrobial activity of essential oil was investigated against twelve bacteria and 5 fungi, by using agar dilution method. Essential oil was effective against Listeria monocytogenes and Saccharomyces cerevisiae, especially.
\end{abstract}

Keywords: Galanthus ikariae, Volatile oil, Antioxidant, Antimicrobial, GS-MS/FID

\footnotetext{
*aa Osman ÜÇÜNCÜ; osmanucuncu@yahoo.com; Tel: (0456) 23310 00-1861; a orcid.org/0000-0003-0858-0188

borcid.org/0000-0002-4336-4002 $\quad{ }^{c}$ orcid.org/0000-0002-5221-1681 $\quad$ orcid.org/0000-0002-3175-6375

e orcid.org/0000-0002-8873-8928 forcid.org/0000-0002-0811-5537

orcid.org/0000-0002-3175-6375
g orcid.org/0000-0003-2800-9376
} 


\section{Giriş}

Amaryllidaceae familyasina ait olan kardelen (Galanthus spp.), ülkemizin kuzey ve doğu bölgelerinde yetişen ve ilkbaharda beyaz renkli çiçek açan soğanlı bir bitki türüdür. Deniz seviyesinden 900-1800 metre yüksekliklerde ve nemli toprakta yetişebilen, $-15^{\circ} \mathrm{C}$ 'ye kadar sıcaklıktan etkilenmeyen bu bitkinin çiçeklenme dönemi ocak ayından mart sonuna kadardır. Karlı günlerde çiçek verdiği ve yılın ilk çiçeği olarak kabul edildiğinden kardelen ismini alan bitki, botanikçiler tarafından ilk olarak soğanlı menekşe olarak tanımlanmıştır. Galanthus cinsinin Doğu ve Kuzey Anadolu'da yetişen yaygın türlerinden bazıları G.ikariae Baker ve G. rizehensis Stern. dir (Brickell, 1984). Dünyada 20 kadar doğal türü bulunan kardelenin Türkiye'de 11 türü yetişir ve bunların 3'ü endemiktir. Bir kardelen türü olan Galanthus ikariae bitkisi Türkiye'de daha çok Artvin, Gümüşhane ve Trabzon yöresinde yayıllış göstermekte olup, halk arasında karga soğanı veya domuz soğanı şeklinde isimlendirilmektedir (Kaya vd., 2002).

Ülkemizde yetişen bazı Galanthus türlerinin yaprak ve gövde kısımlarının geleneksel tedavide adet söktürücü ve kalbi kuvvetlendirici, soğanlarının ise ezilerek çıbanları olgunlaştırmada kullanıldığı bilinmektedir (Baytop, 1999). Ticari olarak ise bazı Galanthus türlerinin soğanları ihraç edilmektedir (Koyuncu, 1997).

Amaryllidaceae familyasına ait olan Galanthus türleri içerdikleri alkaloidlerden ve potansiyel tedavi edici etkilerinden dolayı çok sayıda fitokimyasal çalışmaya konu olmuşlardır. Günümüzde Galanthus cinsi, tedavi değeri olan (Rainer, 1997) ve ilaç olarak kullanılma potansiyeline sahip farkl1 alkaloidleri nedeniyle ilgi çekmektedir (Noyan vd., 1998; Ünver vd., 1999). Galanthamin, likorin, tazettin, galanthin ve sanguinin gibi alkaloidlerin $G$. woronowii Losinks. bitkisinden izole edildiği bildirilmiştir (Sarikaya vd. 2013, Bozkurt vd., 2017). G. woronowii ve G. nivalis bitkilerinin karşılaştırılmalı GC-MS analizlerinde bu bitkilerden sırasıyla 13 ve 42 adet bileşiğin yapısı aydınlatılmıştır (Bokov ve Samylina, 2017). Bokov vd., (2016) başka bir çalışmada ise aynı bitkilerinin metanol ekstraktlarının Amaryllidaceae alkaloid profillerini ortaya çıkartmışlardır. Karimi vd., (2018) yaptıkları bir çalışmada ise $G$. transcaucasicus bitkisinin fitokimyasal değerlendirilmesi ile antioksidan ve antimikrobiyal özelliklerini araştırmışlardır. Farklı bir çalışmada ise G. ikariae bitkisinin alkaloid içeriği araştırılmış ve (+)-9-odimetilhomolikorine, (-)-galanthamin, (+)-3epihidroksibulbispermine ve (+)-tazettin bileşikleri tanımlanmıştır (Sener vd., 1999). Literatürde Galanthus cinsine ait GC-MS ve biyolojik aktivite çalışmaları sınırlı sayıdadır. Son y1llarda Galantus türlerinin potansiyel tedavi edici etki gösterdikleri belirlenen lektin ve Amaryllidaceae alkaloidlerini içerdikleri belirtilmiştir. Nitekim analjezik, antiviral, sitotoksik ve antikolinestaz gibi biyolojik etki gösteren ve Alzheimer hastalığının tedavisinde kullanılan galantamin ve analjezik ile kardiyotonik etkisi olan likorin bu cinse ait türlerde bulunmaktadır (Emir 2010). Bu çalışmada G. ikariae bitkisinin uçucu yağı elde edilerek, kimyasal yapısı aydınlatılmış, antioksidan ve antimikrobiyal özellikleri incelenmiştir.

\section{Materyal ve Metot}

\subsection{Materyal}

İncelenen Galanthus ikariae bitkisi, 2013 y1l Mart ayında Gümüşhane ili Kürtün ilçesi Çayırçukur Köyü'nden (980m, A7, 40 40' 26" kuzey, $39^{\circ} 5^{\prime} 50^{\prime \prime}$ doğu) toplanmıştır. Bitki materyali Giresun Üniversitesi Bulancak UBYO Bitkisel Üretim ve Teknolojileri Bölümü öğretim üyesi Doç. Dr. Mutlu Gültepe tarafindan teşhis edilerek KTUB Gültepe 551 herbaryum numaras1 verilerek, analiz için oda sıcaklığında açık havada kurutulmuş ve uygun koşullarda saklanmıştır.

\subsection{Metod}

\subsubsection{Celevenger Tipi Hidrodestilasyon İşlemi}

Kurutulmuş Galanthus ikariae bitki örneklerinden alınan 75 gramlık toprak üstü kısımlar, küçük parçalara ayrıldıktan sonra 2 L'lik balona konularak üzerine $800 \mathrm{~mL}$ saf su eklenmiştir. Bitki materyali, gömlekli ısıtıcı üzerinde yaklaşık 4 saat isitılmış ve Clevenger tipi cihazda uçucu yağın toplanması sağlanmıştır. Oluşan uçucu yă HPLC kalitesinde $1 \mathrm{~mL}$ n-hekzan'da çözülerek alındıktan sonra koyu renkli şişede ağzı kapatılarak $-18{ }^{\circ} \mathrm{C}^{\prime} \mathrm{de}$ saklanmıştır. Daha sonra uçucu yağ ekstraktından alınan $1 \mu \mathrm{L}$ 'lik çözeltiler GC-MS cihazına enjekte edilerek analizi yapılmıştır (Pino vd., 2005).

\subsubsection{GC-MS Analizleri}

$1 \mathrm{~mL}$ hegzan eklenmiş uçucu yağ ekstraktından alınan $1 \mu$ L'lik çözelti GC-MS cihazına enjekte edilmiş ve kimyasal analizi yapılmıştır. $\mathrm{Bu}$ 
çalışmada yapılan GC-MS analizinde Agilent marka gaz kromatografisi cihazı ile 5977 E Seri GC/MSD marka kütle spektrometresi cihazları kullanılmıştır.

\subsubsection{Bileşenlerin Aydınlatılması}

Uçucu yağların bileşenleri kütle spektrumlarının GC-MS cihazında bulunan NIST, WILEY gibi kütüphanelerle, alıkonma sürelerinin ise literatür verileriyle karşılaştırılması sonucu toplam 41 adet bileşiğin yapısı aydınlatılmıştır (Adams, 2004; Pino vd., 2005; Zhao vd., 2009).

\subsubsection{Antimikrobiyal Aktivite Analizi}

Çalışmada kullanılan mikroorganizmalar Gümüşhane Üniversitesi Gıda Mühendisliği Bölümü laboratuvarlarından temin edilmiştir. Uçucu yağ ekstraktının antimikrobiyal aktiviteleri 12 bakteri ve 5 maya-küf olmak üzere 17 mikroorganizmaya karşı agar difüzyon yöntemi ile belirlenmiştir. Mikroorganizmalar aktifleşmeden 24 saat sonrasındaki 18 saatlik ikinci aktifleştirme işleminden sonra kullanılmıştır( $\left.10^{6} \mathrm{cfu}\right) . \quad \mathrm{Bu}$ amaçla, hazırlanan steril katı besiyerlerine çalışmada kullanılacak mikroorganizmalardan \%1 oranında ilave edilmiş ve petri kutularına dökülüp katılaşmaları beklenmiştir. Daha sonra katılaşan besiyerlerinin üzerine $5 \mathrm{~mm}$ çaplı kuyucuklar açılmıştır. Açılan kuyucuklara, uçucu yağın hegzan ile hazırlanmış farkl1 konsantrasyondaki $(\% 1, \quad 2, \quad 5, \quad 10)$ solüsyonlarından eklenerek, inkübasyon işlemi gerçekleştirilmiştir. Bakteriler $36^{\circ} \mathrm{C}^{\prime}$ de 24 saat, mayalar $32^{\circ} \mathrm{C}$ 'de 48 saat inkübasyona bırakılmıştır. Yeterli süre sonunda gelişme olan zonlar ölçülerek değerlendirme yapılmıştır (Finley ve Given, 1986).

\subsubsection{Antioksidan Aktivite Testleri}

\subsubsection{Serbest Radikal Süpürücü Aktivitenin Belirlenmesi:}

Bitkinin uçucu yağının serbest radikal süpürücü aktivitesi 2,2-difenil-1-pikrilhidrazil (DPPH) kullanılarak Sanchez-Moreno metoduna göre yapılmıştır (Sağdıç ve Özcan, 2003). Metoda göre konsantrasyonları belirli olarak hazırlanan uçucu yağ ve DPPH çözeltileri vorteksle karıştırılarak oda sicaklığında ve karanlıkta 30 dk bekletilmiştir. $517 \mathrm{~nm}$ 'de absorbansı okunarak reaksiyon ortamında kalan DPPH miktarı aşağıdaki formüle göre hesaplanmıştır:

$\%$ İnhibisyon $=$ (Kontrol Absorbans1-Örneğin Absorbans1 / Kontrol Absorbans1) x 10

\subsubsection{Toplam Fenolik Madde Miktarı:}

Folin-Ciocalteu metoduyla toplam fenolik madde tayini Gamez-Meza'e göre yapılmıştır (GámezMeza vd.,1999). Konsantrasyonu belli $0.5 \mathrm{~mL}$ örnek, $2.5 \mathrm{~mL}$ Folin-Ciocaltaeu reaktifi (\%10'luk, $\mathrm{h} / \mathrm{h}$, suda) ve $7.5 \mathrm{~mL} \mathrm{Na} \mathrm{CO}_{3}$ çözeltisi (\%20'lik, $\mathrm{a} / \mathrm{h}$, suda) deney tüpüne karıştırılarak 2 saat oda sıcaklığında bekletilmiştir. Örneklerin absorbansı $765 \mathrm{~nm}$ dalga boyunda köre karşı okunarak toplam fenolik madde miktarlar1; gram ekstraktta mg gallikasite eşdeğer olacak şekilde hesaplanmıştır.

\section{Bulgular ve Tartışma}

Şekil 1'de spektrumu verilen $75 \mathrm{~g}$ kurutulmuş Galanthus ikariae (Amaryllidaceae) bitkisine uygulanan hidrodestilasyon işlemi ile elde edilen uçucu yağda bulunan 41 adet doğal bileşiğin yapıs1, alıkonma zamanları ve kütle spektrumları dikkate alınarak GC cihazında bulunan NIST ve Willey kütüphanelerindeki bileşiklerle ve literatürle karşılaştırılarak ortaya çıkarılmıştır. Uçucu yağın GC analizinde bileşiklerin \% 85.42'lik kısmı tanımlanmıştır. Şekil 1'de görüldüğü gibi bitkinin uçucu yağındaki bileşenler, keskin pikler vermiş, yükssek eşleşme oranları (en az \%87) göstermiş ve alıkonma zamanlarının karşılaştırılması ile kimyasal yapıları aydınlatılmıştır.

Yapıs1 aydınlatılan bileşikler Tablo 1'de görüldügü gibi $\alpha$-terpinolen, geraniol gibi terpen türevleri; hegzanal, $(E)$-2-hegzenal, nonanal, $(E)$ 2-nonenal gibi alifatik aldehidler; naftalen, benzen asetaldehid, 1,3-diklorobenzen gibi aromatik bileşikler ve tetradekanoik asit, hegzadekanoik asit ve linoleik asit gibi yağ asitleri bulunmaktadır. Uçucu yağın ana bileşenleri ise \% 19.05 hekzadekanoik asit, \%14.67 linoleik asit, \% 11.49 2-tridekanon ve \% 6.97 oranında linoleik asit metil ester bileşikleridir. Uçucu yağın içerisinde yağ asitleri ve esterleri ana bileşen sınıfını oluşturmaktadır. Literatürde Galanthus cinsi üyeleri üzerine GC-MS çalışmaları sınırlı sayıdadır. Bokov ve Samylina (2017) tarafindan gerçekleştirilen çalışmada $G$. woronowii ve $G$. nivalis bitkilerinin metanol ekstraktlarının karşılaştırılmalı GC-MS analizleri yapılmıştır. $G$. woronowii bitkisinde etil linoleat, 2,9,10trimetoksi-(1 $\alpha, 2 \alpha)$-3,12-didehidrogalantan-1-ol ve etil- $\alpha$-D-glukopyranosid bileşikleri, G. nivalis bitkisinde ise evoglukosan, 4,5-etilen-8,9dimetoksi-6-fenantridon ve 1-metoksi-3-(2hidroksietil)-nonan bileşikleri ana bileşenler olarak belirlenmiştir. G. transcaucasicus bitkisi 
üzerine yapılan GC-MS çalışmasında ise 2furankarboksialdehid, 2,3-butandiol, ve asetik asit ana bileşenler olduğu ortaya konulmuştur (Karimi vd., 2018). Kimyasal içeriklerin farklılıkları metanol ekstraktlarından ve kullanılan GC kolonunun farklı olmasından kaynaklanmaktadır.

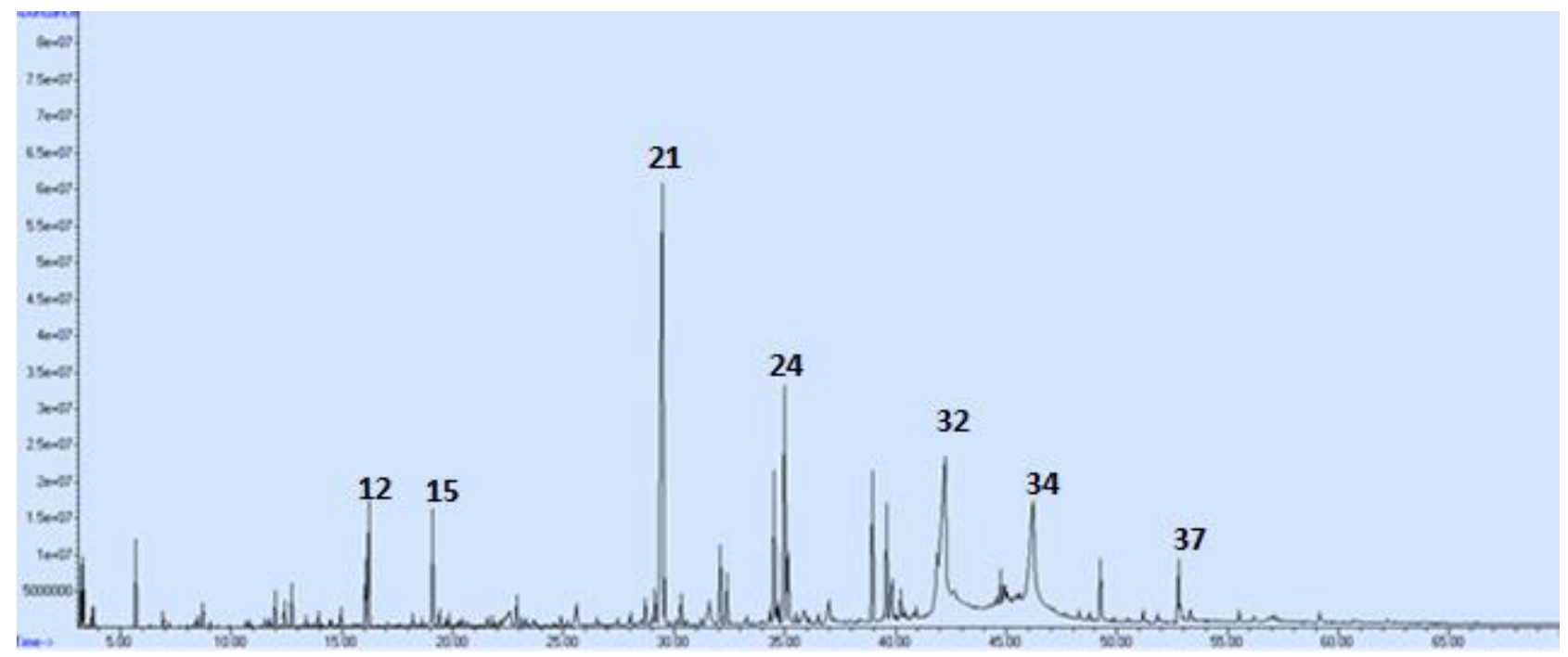

Şekil 1. G. ikariae bitkisinin GC-MS spektrumu

Tablo 1. G. ikariae bitkisinin GC-MS analiz sonuçları

\begin{tabular}{lccccc}
\hline & Bileşiğin İsmi & RT & Deneysel RI & Eşleşme Oranı \% & Pik Alan \\
\hline $\mathbf{1}$ & 1-Hegzanal & 5.685 & 805 & 95 & 0.65 \\
$\mathbf{2}$ & 3-Siklohepten-1-on & 6.361 & 822 & 91 & 0.04 \\
$\mathbf{3}$ & 5,5-dimetil-2-etil-1,3-siklopentadien & 6.925 & 841 & 87 & 0.12 \\
$\mathbf{4}$ & (2E)-Hekzenal & 7.196 & 850 & 97 & 0.06 \\
$\mathbf{5}$ & 2-Heptanol & 10.683 & 956 & 95 & 0.19 \\
$\mathbf{6}$ & 2-pentil furan & 11.989 & 992 & 91 & 0.36 \\
$\mathbf{7}$ & 1,3-Dikloro benzen & 12.735 & 1013 & 97 & 0.92 \\
$\mathbf{8}$ & Benzen asetaldehid & 13.939 & 1040 & 94 & 0.19 \\
$\mathbf{9}$ & (2E)-Oktenal & 14.481 & 1049 & 95 & 0.11 \\
$\mathbf{1 0}$ & 1-Oktanol & 14.956 & 1050 & 87 & 0.29 \\
$\mathbf{1 1}$ & a-Terpinolen & 15.591 & 1089 & 95 & 0.15 \\
$\mathbf{1 2}$ & Nonanal & 16.204 & 1106 & 91 & 1.97 \\
$\mathbf{1 3}$ & 2-etil-hekzanoik asit & 17.030 & 1122 & 90 & 0.14 \\
$\mathbf{1 4}$ & (E)-2-Nonenal & 18.203 & 1161 & 95 & 0.36 \\
$\mathbf{1 5}$ & Naftalen & 19.096 & 1186 & 97 & 1.62 \\
$\mathbf{1 6}$ & Dekanal & 19.846 & 1207 & 91 & 0.55 \\
$\mathbf{1 7}$ & Geraniol & 21.570 & 1250 & 93 & 0.25 \\
$\mathbf{1 8}$ & Nonanoik asit & 22.529 & 1270 & 92 & 0.83 \\
$\mathbf{1 9}$ & 2-Undekanon & 22.894 & 1295 & 97 & 0.72 \\
$\mathbf{2 0}$ & 1-Dodekanol & 28.708 & 1468 & 87 & 1.09 \\
$\mathbf{2 1}$ & 2-Tridekanon & 29.437 & 1495 & 95 & 11.49 \\
$\mathbf{2 2}$ & Dodekanoik asit & 31.582 & 1570 & 99 & 1.09 \\
$\mathbf{2 3}$ & Benzofenon & 33.275 & 1631 & 95 & 0.33 \\
$\mathbf{2 4}$ & 2,11-Tridekandion & 34.980 & 1696 & 91 & 5.78 \\
$\mathbf{2 5}$ & 14-Metil pentadekanoik asit & 35.869 & 1731 & 98 & 0.85 \\
$\mathbf{2 6}$ & 2- Fenil metilen oktanal & 36.504 & 1754 & 99 & 0.27 \\
$\mathbf{2 7}$ & Tetradekanoik asit & 36.979 & 1772 & 99 & 1.58 \\
$\mathbf{2 8}$ & 6,10,14-trimetil-2-pentadekanon & 38.951 & 1848 & 96 & 1.97 \\
$\mathbf{2 9}$ & Fitalik asid, isobutil oktil ester & 39.595 & 1874 & 90 & 3.21 \\
\hline
\end{tabular}


Tablo 1. devam1

\begin{tabular}{lccccc}
\hline & Bileşiğin İsmi & RT & Deneysel RI & Eşleşme Oranı \% & Pik Alanı \\
\hline $\mathbf{3 0}$ & Nonadekan & 40.235 & 1899 & 92 & 1.20 \\
$\mathbf{3 1}$ & Hekzadekanoik asit metil ester & 40.906 & 1927 & 96 & 0.82 \\
$\mathbf{3 2}$ & Hekzadekanoik asit & 42.190 & 1978 & 99 & 19.05 \\
$\mathbf{3 3}$ & Metil linoleat & 44.753 & 2092 & 99 & 6.97 \\
$\mathbf{3 4}$ & Linoleik asit & 46.187 & 2137 & 99 & 14.67 \\
$\mathbf{3 5}$ & (Z)-9-Trikosen & 48.746 & 2275 & 99 & 0.56 \\
$\mathbf{3 6}$ & 2,6,10-Trimetil, 14-neofitadien & 51.180 & 2393 & 96 & 0.41 \\
$\mathbf{3 7}$ & Linoleik asid, butil ester & 52.779 & 2475 & 90 & 1.39 \\
$\mathbf{3 8}$ & Pentakosan & 53.303 & 2502 & 74 & 1.18 \\
$\mathbf{3 9}$ & $(Z, Z)-10,12-$ Hekzadekadien-1-ol asetat & 54.529 & 2558 & 90 & 0.52 \\
$\mathbf{4 0}$ & Heptakosan & 57.075 & 2700 & 96 & 1.38 \\
$\mathbf{4 1}$ & Nonakosan & 62.223 & 2900 & 98 & 0.14 \\
\hline & & & & Toplam\% & 85.42 \\
\hline
\end{tabular}

*RT: Retention time, RI: Retention index

Galanthus ikariae bitkisinin uçucu yağ ekstraktlarının seçilen test mikroorganizmalara karş1 inhibisyon seviyeleri Tablo 2'de gösterilmiştir. Kullanılan uçucu yağın \%1'lik konsantrasyonda $B$. cereus, E.coli, E. coli O157:H7, L. monocytogenes ve S. aureus'a karş1 etkili olduğu görülmüştür. Antimikrobiyal çalışma sonucunda uçucu yağın antifungal etkisinin sadece $S$. cerevisiae mikroorganizmasına karşı olduğu tespit edilmiştir. Karimi vd. 2018'in $G$. transcaucasicus bitkisinin metanol ekstraktlarının B. subtilis, B. cereus, S. aureus, E. coli ve $P$. aeruginosa bakterilerine karş1 etkili olduğu görülmüştür. $\mathrm{Bu}$ bitkinin sergilediği yüksek antimikrobiyal aktivitenin mikrobiyal bazdaki farklılığın yanısıra, içerdiği fenoliklere, flavonoidlere ve uçucu bileşiklere bağl1 olduğu belirtilmiştir (Karimi vd., 2018). Yapılan başka bir çalışmada $G$. ikariae bitkisindeki analjezik, kardiyotonik, antienflamatuar, antimalarial ve antitümör gibi birçok biyolojik aktivite gösteren, likorin yüzdesi 0,0043 olarak bulunmuştur (Sener vd., 1999). Aynı çalışmada $G$. elwesii ve $G$. ikariae bitkilerinin bazı biyolojik aktiviteleri incelenmiştir. $\mathrm{Bu}$ bitkilerin etanol ekstratlarının antibakteriyal, antifungal, antiplatelet, antimalarial aktivitelerinin olmadığı sadece $G$. elwesii bitkisinin insektisidal aktivite gösterdiği görülmüştür (Sener vd., 1999).

Tablo 2. Galanthus ikariae Baker, bitkisinin uçucu yağının antimikrobiyal aktivitesi (mm)

\begin{tabular}{ccccc}
\hline & $\% 1$ & $\% 2$ & $\% 5$ & $\% 10$ \\
\hline Bakteri & - & & & - \\
Yersinia pseudotuberculosis & $6.62 \pm 0.10$ & - & - & - \\
Bacillus cereus & - & - & - & - \\
Bacillus subtilis & - & - & - & - \\
Enterobacter cloacae & $7.40 \pm 0.15$ & - & - & - \\
Escherichia coli & $5.37 \pm 0.10$ & - & - & - \\
Escherichia coli O157:H7 & - & - & - & - \\
Klebsiella pneumoniae & $8.28 \pm 0.10$ & - & - & - \\
Listeria monocytogenes & - & - & - & - \\
Proteus vulgaris & - & - & - & - \\
Pseudomonas aeruginosa & - & - & - & - \\
Salmonella Typhimurium & $5.29 \pm 0.10$ & - & - & - \\
Staphylococcus aureus & - & - & - & - \\
Maya-Küf & $10.3 \pm 0.10$ & - & - & - \\
Saccharomyces cerevisia & - & - & - & - \\
Candida albicans & - & - & - & - \\
Zygosaccharomyces bailii & - & - & - & - \\
Zygosaccharomyces rouxii & - & - & - & - \\
Penicillium & & &
\end{tabular}


Bitkiden elde edilen uçucu yağın 2,2-difenil-1pikrilhidrazin (DPPH) üzerindeki serbest radikal süpürücü madde miktarı ile Folin-Ciocalteu metoduyla da toplam fenolik madde miktarı sirasiyla $342.22 \mathrm{mg} / \mathrm{mL}$ GAE ve $\% 55.92$ olarak bulunmuştur. Ayrıca toplam fenolik madde miktarı hesaplanmasında kullanılan gallik asit standart kurvesi çizilmiş ve $\mathrm{R}^{2}$ değeri 0,0997 olarak bulunmuştur. Ay (2018) yaptığ çalışmada Galanthus elwesii bitkisinin çiçek, yaprak, gövde, kök ve soğanlarının etanol ekstratlarının toplam fenolik ve flavonoid içeriğini belirlemiştir. İlgili çalışmada bitki organları bazında antioksidan aktivitenin değişebildiği belirtilmiş ve bitkinin fenolik içeriği olgunlaşma aşamasındaki soğanlarında en yüksek (42.63 $\mathrm{mgGA} / \mathrm{mg})$, olgunlaşma aşamasındaki köklerde $(18.15 \mathrm{mgGA} / \mathrm{mg})$ ise en düşük olarak belirlenmiştir. Çalışmamızda ise G. ikariae bitkisinin uçucu yağının antioksidan aktiviteye sahip olduğu tespit edilmiş ve uçucu yağ ekstraktının DPPH radikaline karşı radikal süpürücü aktivitesi \%55.92 olarak bulunmuştur.

Bitkilerde bulunan diğer bileşikler için de farklı çalışma yöntemleriyle yapı aydınlatılması yapılabilir. Yapısı aydınlatılan bileşiklerin çoğunluğunu aldehid ve yağ asitleri oluşturmaktadır. $\mathrm{Bu}$ bileşik türlerinin özellikle ilaç, kozmetik ve gıda sanayisi gibi günlük yaşantıda pek çok kullanım alanının bulunması bu tür bitkilere olan ilgiyi artırmaktadır.

\section{Sonuç}

$\mathrm{Bu}$ çalışma $G$. ikariae bitkisinin toprak üstü kısımlarının uçucu yağının kimyasal içeriği ve biyolojik özelliklerinin (antioksidan ve antimikrobiyal) incelendiği literatürdeki ilk çalışmadır. Çalışmada, uçucu yağ GC-MS/FID ile analiz edilerek 41 adet bileşiğin yapısı aydınlatılmıştır. Uçucu yağda hegzadekanoik asit, linoleik asit, 2-tridekanon, linoleik asit metil ester bileşiklerinin ana bileşenler olduğu bulunmuştur. Potansiyel biyolojik etki göstereceği düşünülen uçucu yağın agar-kuyucuk yöntemi ile yapılan antimikrobiyal aktivite testi sonucuna göre Listeria monocytogenes bakterisi ve Saccharomyces cerevisiae mayasına karşı etkili olduğu görülmüştür. Ayrıca bitkiye ait uçucu yağın antioksidan özelliklerinin belirlenmesi için yapılan çalışmalarda toplam fenolik miktarı ve radikal süpürücü aktivitesi (DPPH) sirasiyla $342.22 \mathrm{mg} / \mathrm{mL}$ GAE ve $\% 55.92$ bulunmuştur. $\mathrm{Bu}$ çalışmadaki veriler, ilerleyen dönemlerde Galanthus cinsi üzerine yapılacak çalışmalara katkıda bulunabilir. Amaryllidaceae familyasına ait olan bitkinin biyolojik aktif olduğu belirtilen galantamin ve likorin alkaloitleri içeriği araştırılarak kaliteli bir drog ortaya çıkarılabilir.

\section{Kaynaklar}

Adams, R.P., 1997. Identification of essential oil components by gas chromatography/mass spectroscopy. Journal of the American Society for Mass Spectrometry 8(6), 671-672.

Ay, B.E., Açikgöz, M.A., Yarilgaç, T. Ve Kara, M., 2018. Assessment of Antioxidant Activity of Giant Snowdrop (Galanthus elwesii Hook) Extracts with Their Total Phenol and Flavonoid Contents. Indian Journal of Pharmaceutical Education and Research 52(4) 128-132.

Baytop, T., 1999. Bitkiler İle Tedavi (Geçmişte ve Bugün). İstanbul, Nobel Tip Kitabevleri, $480 \mathrm{~s}$.

Brickell, C. D., 1984. Galanthus L. In: Flora of Turkey and the Est Aegean Islands, in: Davis, P.H. (Ed.), Vol. 8, Edinburgh University Press, EdinBurgh ISBN: 9780852244944, pp. 365-372.

Bokov, D.O., Samylina, I. A. ve Nikolov, S. D., 2016. Amaryllidaceae alkaloids GC/MS analysis in Galanthus woronowii and Galanthus nivalis of Russian origin. Research Journal of Pharmaceutical Biological and Chemical Sciences 7(6), 1625-1629.

Bokov, D.O. ve Samylina, I.A., 2017. Comparison of the Chemical Compositions of Galanthus woronowii Losinsk. and Galanthus nivalis L. Homeopathic Mother Tinctures by Gas Chromatography with Mass-Selective Detection. Pharmaceutical Chemistry Journal 50(10), 659-667.

Bozkurt, B., Emir, A., Kaya, G.İ., Onur, M.A., Berkov, S., Bastida, J. ve Unver Somer N., 2017. Alkaloid profiling of Galanthus woronowii Losinsk. by GC-MS and evaluation of its biological activity. Marmara Pharmaceutical Journal 21(4), 915-920.

Emir, A., 2010. Galanthus woronowii Losinsk. Bitkisinin Kalite Kontrol Açısından Değerlendirilmesi, Yüksek Lisans Tezi, Ege Üniversitesi Sağlık Bilimleri Enstitüsü, İzmir, $147 \mathrm{~s}$.

Finley, J.W. ve Given Jr, P., 1986. Technological necessity of antioxidants in the food industry. Food and Chemical Toxicology, 24(10-11), 999-1006.

Gámez-Meza, N., Noriega-Rodríguez, J.A., MedinaJuárez, L.A., Ortega-García, J., CázarezCasanova, R. ve Angulo-Guerrero, O., 1999. Antioxidant activity in soybean oil of extracts 
from Thompson grape bagasse. Journal of the American Oil Chemists' Society 76(12), 1445.

Karimi, E., Mehrabanjoubani, P., Homayouni-Tabrizi, M., Abdolzadeh, A. ve Soltani, M., 2018. Phytochemical evaluation, antioxidant properties and antibacterial activity of Iranian medicinal herb Galanthus transcaucasicus Fomin. Journal of Food Measurement and Characterization, 12(1), 433-440.

Kaya, G. İ., Kıvçak, B. ve Gözler, B., 2002. Galanthus nivalis L. subsp. cilicicus (Baker) GottliebTannenhain bitkisinden hazırlanan herba ve bulbus galanthi drogları üzerinde DAB 10'A göre yapılan kalite kontrol çalışmaları. 14. Bitkisel İlaç Hammaddeleri Toplantısı, 29-31 Mayıs 2002, Eskişehir, 199-202.

Koyuncu, M., 1997. Türkiye'den İhraç Edilen Geofitlerin Korunması ve Üretimi Konusunda Gelişmeler, In: XI. Bitkisel İlaç Hammaddeleri Toplantısı Bildiri Kitabı (editörler: M. Kükcüoğlu, KHC. Baser), Ankara Üniversitesi Eczacılık Fakültesi, 57-62.

Noyan, S., Rentsch, G.H., Önür, M.A., Gözler, T., Gözler, B., ve Hesse, M., 1998. The Gracilines: a novel subgroup of the Amaryllidaceae Alkaloids. Org-Chem.Inst., 29(51), 1777-1791.

Pino, J. A., Mesa, J., Muñoz, Y., Martí, M. P. ve Marbot, R., 2005. Volatile components from mango (Mangifera indica L.) cultivars. Journal of Agricultural and Food Chemistry, 53(6), 2213-2223,

Rainer, M., 1997. Galanthamine in Alzheimer's disease. CNS Drugs, 7(2), 89-97.

Sağdıç, O. ve Özcan, M., 2003. Antibacterial activity of Turkish spice hydrosols. Food Control, 14(3), 141-143.

Sarikaya, B.B., Kaya, G.I., Onur, M.A., Bastida, J. ve Somer, N.U., 2013. Phytochemical investigation of Galanthus woronowii. Biochemical Systematics and Ecology, 51, 276-279.

Sener, K., Koyuncu, M., Bingöl, F. ve Muhtar V., 1999. Production of bioactive alkaloids from Turkish geophytes. IUPAC, 23-27 November 1997, Phuket, Thailand. 1-7.

Ünver, N., Gözler, T., Walch, N., Gözler, B., ve Hesse, M., 1999. Two novel dinitrogenous alkaloids from Galanthus plicatus subsp. byzantinus (Amaryllidaceae). Phytochemistry, 50(7), 12551261.

Zhao, C., Zeng, Y., Wan, M., Li, R., Liang, Y., Li, C., Zeng , Z. ve Chau, F.T., 2009. Comparative analysis of essential oils from eight herbal medicines with pungent flavor and cool nature by GC-MS and chemometric resolution methods. Journal of Separation Science, 32(4), 660-670. 